\title{
Opioid Free Cardiac Anesthesia
}

\author{
Karunakaran Ramaswamy ${ }^{1,2}$ \\ ${ }^{1}$ Department of Clinical Anesthesiology, Weill Cornell Medical \\ College, Doha, Qatar \\ 2Department of Anesthesiology Sidra Medicine, Doha Qatar
}

\begin{abstract}
Address for correspondence Karunakaran Ramaswamy, MBBS, FRCA, MBA, Department of Clinical Anesthesiology, Weill Cornell Medical College, Doha, Qatar (e-mail: ramaswamy.karunakaran@gmail.com).
\end{abstract}

\begin{abstract}
Keywords

- cardiac pain

- opoid

- opoid free anesthesia

Opioids are one of the effective forms of analgesia for acute pain in the perioperative period but, with overprescription, have become detrimental to public health. There has been a steady increase in opioid consumption and the number of opioid-related deaths, and the U.S. government has declared the opioid epidemic as a public health emergency.Anesthesiologists have a responsibility as the first exposure to opioids was during the perioperative period in the majority of cases. Acute tolerance and hyperalgesia are well known after opioid use in the postoperative opioid further increasing opioid consumption. More importantly, anesthesiologists have no control after the postoperative period, where the prescriptions continue to be repeated from general practice physicians. We have a moral responsibility to reduce opioid use to avoid it if feasible.
\end{abstract}

Opioids are one of the effective forms of analgesia for acute pain in the perioperative period but, with overprescription, have become detrimental to public health. There has been a steady increase in opioid consumption and the number of opioid-related deaths, and the U.S. government has declared the opioid epidemic as a public health emergency. ${ }^{1}$

Anesthesiologists have a responsibility as the first exposure to opioids was during the perioperative period in the majority of cases. ${ }^{2}$ Acute tolerance and hyperalgesia are well known after opioid use in the postoperative opioid further increasing opioid consumption. More importantly, anesthesiologists have no control after the postoperative period, where the prescriptions continue to be repeated from general practice physicians. ${ }^{2}$ The graph below demonstrates a morphine equivalent opioid prescription after common surgical procedures in the United Kingdom. We have a moral responsibility to reduce opioid use to avoid it if feasible (-Figs. 1 and $\mathbf{2}$ ).

There has been a push for the avoidance of opioid use recently with increased emphasis on enhanced recovery and earlier discharge from hospital, side effect profile of opioids, increased use of ultrasound-guided regional anesthesia and plane blocks, and safer alternatives. ${ }^{3,4}$

published online March 27, 2021
DOI https://doi.org/ $10.1055 / \mathrm{s}-0041-1723931$ ISSN 2457-0206.
Opioid free anesthesia (OFA) has these basic foundations. Pain can be controlled by means other than opioids, sympathetic response does not mean pain and could be due to other causes, a form of processed EEG monitoring to monitor the depth of anesthesia and pain is mandatory. ${ }^{5}$

There are some misconceptions about OFA that patients will be in pain, it is expensive and the need for multiple infusions which are unfounded.

The common medications used for OFA are as follows:

- Dexmedetomidine: This has revolutionized OFA as it can be used right from induction, maintenance, in postoperative care, for smoother extubation, and as patient-controlled analgesia. The usual dose of dexmedetomidine is $1 \mathrm{mcg} / \mathrm{kg}$ over 10 minutes as an initial dose followed by maintenance 0.3 to $0.7 \mathrm{mcg} / \mathrm{kg} /$ hour. This infusion can be taken to intensive care unit as it is an excellent agent for sedation in the intensive care unit and can be continued for smooth extubation. It can also be used as a PCA post extubation. This does not have the respiratory depression effect of opioids, nausea, or vomiting. The patients are sedated and respond to verbal commands. ${ }^{5}$ Hemodynamic effects have been studied in detail and a recent meta analysis is a good reference. ${ }^{5}$ (c) 2021. Official Publication of The Simulation Society (TSS), accredited by International Society of Cardiovascular Ultrasound (ISCU).

This is an open access article published by Thieme under the terms of the Creative Commons Attribution-NonDerivative-NonCommercial-License, permitting copying and reproduction so long as the original work is given appropriate credit. Contents may not be used for commercial purposes, or adapted, remixed, transformed or built upon. (https://creativecommons.org/licenses/by-nc-nd/4.0/)

Thieme Medical and Scientific Publishers Pvt. Ltd. A-12, 2nd Floor, Sector 2, Noida-201301 UP, India 


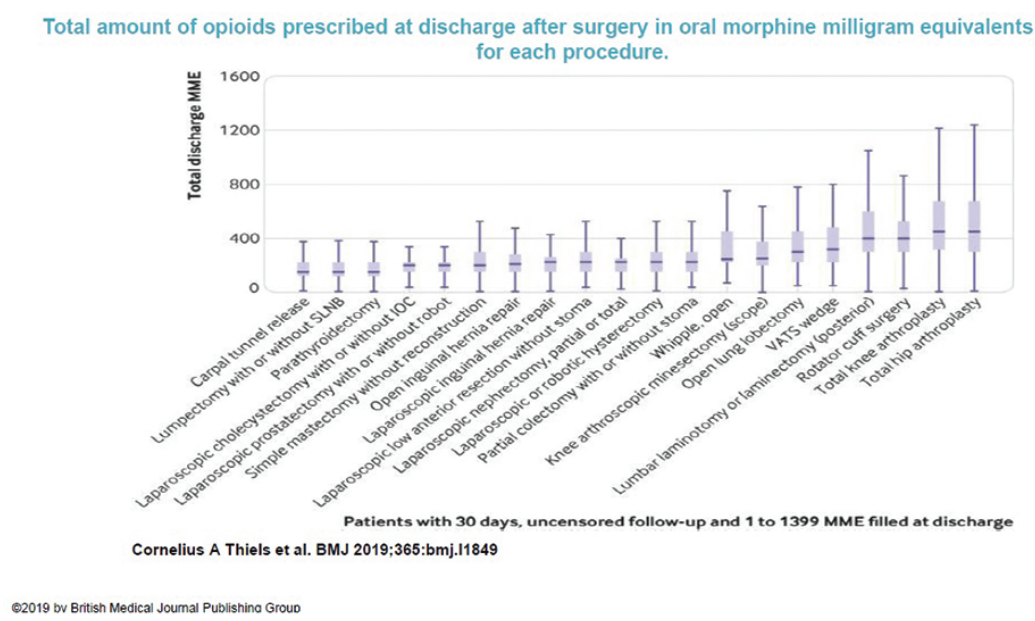

Fig. 1 Total oral morphine equivalents (MME) prescribed at discharge after common surgical procedures.

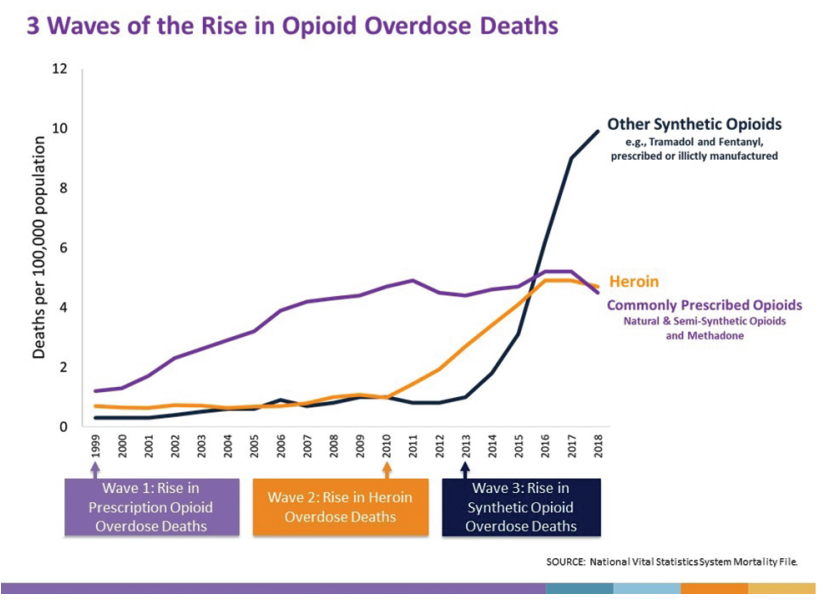

Fig. 2 Three waves of the rise in opioid overdose deaths.

- Magnesium: This has been a cornerstone in cardiac anesthesia due to multiple beneficial effects. It is an excellent opioid-sparing medication and is used as a loading dose of 30 to $50 \mathrm{mg} / \mathrm{kg}$ given over 10 to 15 minutes and an infusion $(8-15 \mathrm{mg} / \mathrm{kg} / \mathrm{h})$, beware of hypotension, muscle weakness, and bleeding. A bolus dose in itself is useful if there is a paucity of infusions.

- Ketamine: This is an excellent analgesic and an opioid-sparing agent. It is best used after the induction of anesthesia to avoid postoperative delirium. A bolus dose of 0.1 to $0.3 \mathrm{mg} / \mathrm{kg}$ after induction which can then be either continued as an infusion or hourly bolus is effective. ${ }^{5}$

- Lignocaine: This has been extensively studied in cardiac anesthesia. The usual dose is $1 \mathrm{mg} / \mathrm{kg}$ bolus and infusion 0.5 to $3 \mathrm{mg} / \mathrm{kg} /$ hour. This is an excellent opioid sparring agent and also has an anti-inflammatory effect and safety profile. ${ }^{6,7}$ Please beware of using other local anesthetics for blocks and calculate the local anesthetic doses carefully.

- Dexamethasone: $0.1 \mathrm{mg} / \mathrm{kg}$ is another excellent analgesic and opioid-sparing agent.

Majority of these medications are already used in cardiac surgery and can be given as bolus requiring very minimal infusions. Dexmedetomidine has come into a mainstay as it can be used for the entire perioperative period with a favorable hemodynamic and side-effect profile.

Regional anesthesia, especially multiple fascial plane blocks (serratus anterior plane, pectoralis fascial block, and erector spinae block), are making a foray into cardiac surgery and have proven to be opioid sparing and promoting early extubation.

In summary, OFA is a necessity with prehabilitation, enhanced recovery programs, patient safety initiatives, and an international push to avoid opioids due to the opioid epidemic.

\section{Funding \\ None.}

\section{Conflict of Interest}

None declared.

\section{References}

1 Hedegaard H, Warner M, Miniño AM. NCHS Data Brief, No. 273. Available at: https://www.cdc.gov/nchs/data/databriefs/ db273.pdf. Accessed February 2017

2 Koepke EJ, Manning EL, Miller TE, Ganesh A, Williams DGA, Manning MW. The rising tide of opioid use and abuse: the role of the anesthesiologist. Perioper Med (Lond) 2018;7(1):16

3 Mulier J, Opioid free general anesthesia: a paradigm shift? Rev Española Anestesiol y Reanim2017;64 (8):427-30

4 Levy N, Quinlan J, El-Boghdadly K, et al. An international multidisciplinary consensus statement on the prevention of opioid-related harm in adult surgical patients. Anaesthesia 2020

5 Lavand'homme P, Estebe JP. Opioid-free anesthesia: a different regard to anesthesia practice. Curr Opin Anaesthesiol 2018;31(5):556-561

6 Gholipour Baradari A, Habibi MR, Habibi V, Nouraei SM. Administration of lidocaine to prevent cognitive deficit in patients undergoing coronary artery bypass grafting and valve plasty: a systematic review and meta-analysis. Expert Rev Clin Pharmacol 2017;10(2):179-185

7 Klinger RY, Cooter M, Berger M, et al; Neurologic Outcomes Research Group (NORG) of The Duke Heart Center. Effect of intravenous lidocaine on the transcerebral inflammatory response during cardiac surgery: a randomized-controlled trial. Can J Anaesth 2016;63(11):1223-1232 